Head has emphasised the fact that sensory experience can only form part of a consecutive consciousness by virtue of the coherence which otherwise isolated incidents receive from the projected aspects of sensation. The activity of the cerebral cortex is essential for giving us our conceptions of coherence both in space and in time. Without the ability to refer the results of our sensations to the outside world - to some definite locality in space--the material stimulus would fail to convey any ideas of size, shape, weight, texture, and intensity.

Appreciation of the nature of the objects and events happening in the outside world are dependent upon certain cortical developments which did not occur until man's immediate ancestors were assuming human qualities. The attainment of the realisation of space and time, and the faculty of recognising objects by their shape, colour, size, and texture, marked the transformation of the ape into a man. For the ability to appreciate these things made it biologically useful for him to devise names for things, and so initiated the development and use of language with all that language implies in vastly increased capacity for thinking in symbols of value to himself and intelligible to others.

By the development of this line of argument, the origin of speech can be brought into logical connexion with the other factors that are expressed in the expansion of the parietal, prefrontal and temporal cortex.

In the primitive human brain, such as the endocranial cast of Pithecanthropus enables us to picture, there is a very pronounced local expansion of the posterior part of the second temporal convolution. This can have only one meaning - the fact that in the earliest known member of the human family there was a sudden expansion of the acoustic territory for the appreciation of some sort of speech.

Primitive speech, apart from mere emotional cries such as all animals endowed with a true sense of hearing emit, no doubt began with imperative verbs differing only in their variety and fuller meaning from instinctive cries. But when names were invented, at first by the definition of a visual experience for which a verbal symbol was devised, it became possible for men to communicate one with the other in sentences of two words after the manner of Alfred Jingle in "Pickwick Papers."

It required a much more elaborate cultivation of the acoustic territories of the cortex before real sentences were devised by the syntactic process of linking together a series of words to express a meaning which was not simply that of the individual words or the combination of them, but so to speak a glorified word with an individuality and a meaning of its own and a rhythm of enunciation somewhat akin to music. As a complement to this power of controlled expression of highly complex acoustic symbols, which is made possible by physiological dispositions in the temporal area, there is a wider understanding of the significance of the symbolism so elaborated, which apparently is made possible by the development of the parietal area (supramarginal convolution). This semantic aspect of speech-the capacity for understanding the deeper significance of words and the wider meaning of the whole sentence-is really part of the process of true comprehension of the aim and purpose of speech, thought and action. It is dependent upon the complete integrity of the cortical connexions linking the tactile with the visual and acoustic areas. The functions of this parietal territory are as significant for the real understanding of events as the prefrontal territories are for the attainment of muscular skill, although in all its activities almost every part of the cortex plays its part.

When man began really to examine the objects around him he did not neglect the study of himself. The knowledge he accumulated of the world included a knowledge of his own body and the estimation of the æsthetic qualities of his fellows, for vision came to acquire an increasing influence in his selection of sexual mates; and it is possible that in the case of the human family Darwin's claim for sexual selection may find much ampler confirmation than most biologists are inclined to attach to it in the case of other organisms. No one can question the appeal of physical beauty to mankind, and it is difficult to believe that an attraction so universal and deepseated could possibly have been devoid of effect in the process of transmuting the uncouth form of an ape into the graceful figure of a human being.

Man did not examine merely the physical form of himself and mankind in general; he studied the behaviour of his fellows, and by introspection examined his own thoughts and feelings, and constructed his conceptions of time, space and materials. In his attempts to interpret what he saw and learned by experiment, he tried to understand such of the forces of Nature as seemed to affect his welfare. Out of such gropings there emerged the earlier theories of physics and biology, which became stereotyped by tradition. At every stage of his progress toward a fuller enlightenment, such speculations became for the vast majority of mankind a simple device for escape from the necessity of thinking. But if such traditional evasions were a source of comfort to the many they have ever been a hindrance to the real thinker striving after a consistent and really satisfying explanation of natural phenomena and human history.

\title{
Atomic Species and their Abundance on the Earth.
}

\section{By Dr. F. W. Aston, F.R.S.}

THE relative abundance of the different elements has always been of great interest to chemists. Attention was directed to the relation between abundance and atomic number first by Harkins (Jour. Amer. Chem. Soc. 39, p. 856 , I917 ; also NATURE, April $x_{4}$, I92I, p. 202), who showed that elements of even atomic number predominated to a very marked degree not only in the earth's crust but also in such extra-terrestrial matter as meteorites. Since there is now available definite information on the constitution, isotopic or otherwise, of so many of the elements, it is of interest to extend this inquiry to individual species

NO. 2837 , VOL. II 3$]$ 
of atoms. The accompanying diagram (Fig. r) represents the relative abundance of the different types of atoms composing the first 39 elements. Although these number less than half the elements known yet, owing to the great preponderance of the lighter elements in terrestrial matter, they represent a surprisingly large percentage, being more than 99.8 by weight of all such matter available for chemical analysis.

The mass-number of each species of atom, that is to say its whole number atomic weight or the number of protons in its nucleus, is plotted against the logarithm to base 1o of the total number of gram-atoms on the earth. The latter figure is arrived at in the following manner. The earth is assumed for the purposes of this calculation to consist of a lithosphere of mass $5.98 \times 10^{27}$ $\mathrm{gm}$. having the average composition of the igneous rocks, a hydrosphere of mass $\mathrm{I} \cdot 45 \times 1 \mathrm{I}^{24} \mathrm{gm}$. of water, are considering $\mathrm{x} \cdot 73 \times \mathrm{ro}^{26}$ gram-atoms containing very nearly $10^{50}$ of type $\mathrm{O}^{16}$ in all. Of the next most abundant type, $\mathrm{Si}^{28}$, there are about one-third that number. The types belonging to odd and even atomic number are distinguished from each other and a continuous connecting line is drawn. In the case of isobaric pairs this line is duplicated, making the diagram somewhat complicated in the region of krypton. It is of interest to note that the contribution of hydrogen atoms from the sea is barely distinguishable on this diagram, while that of oxygen atoms from the sea and air combined is entirely insignificant.

The preponderance of elements of even atomic number is well shown by the peaks $8 \mathrm{O}^{16},{ }_{4} \mathrm{Si}^{28}, 20 \mathrm{Ca}^{40}$, $22 \mathrm{Ti}^{48}, 26 \mathrm{Fe}^{56}, 3^{8} \mathrm{Sr}^{88}$, which have an enormous significance on a log scale of this kind. The outstanding importance of atomic weights of type $8 \mathrm{n}$ is also brought

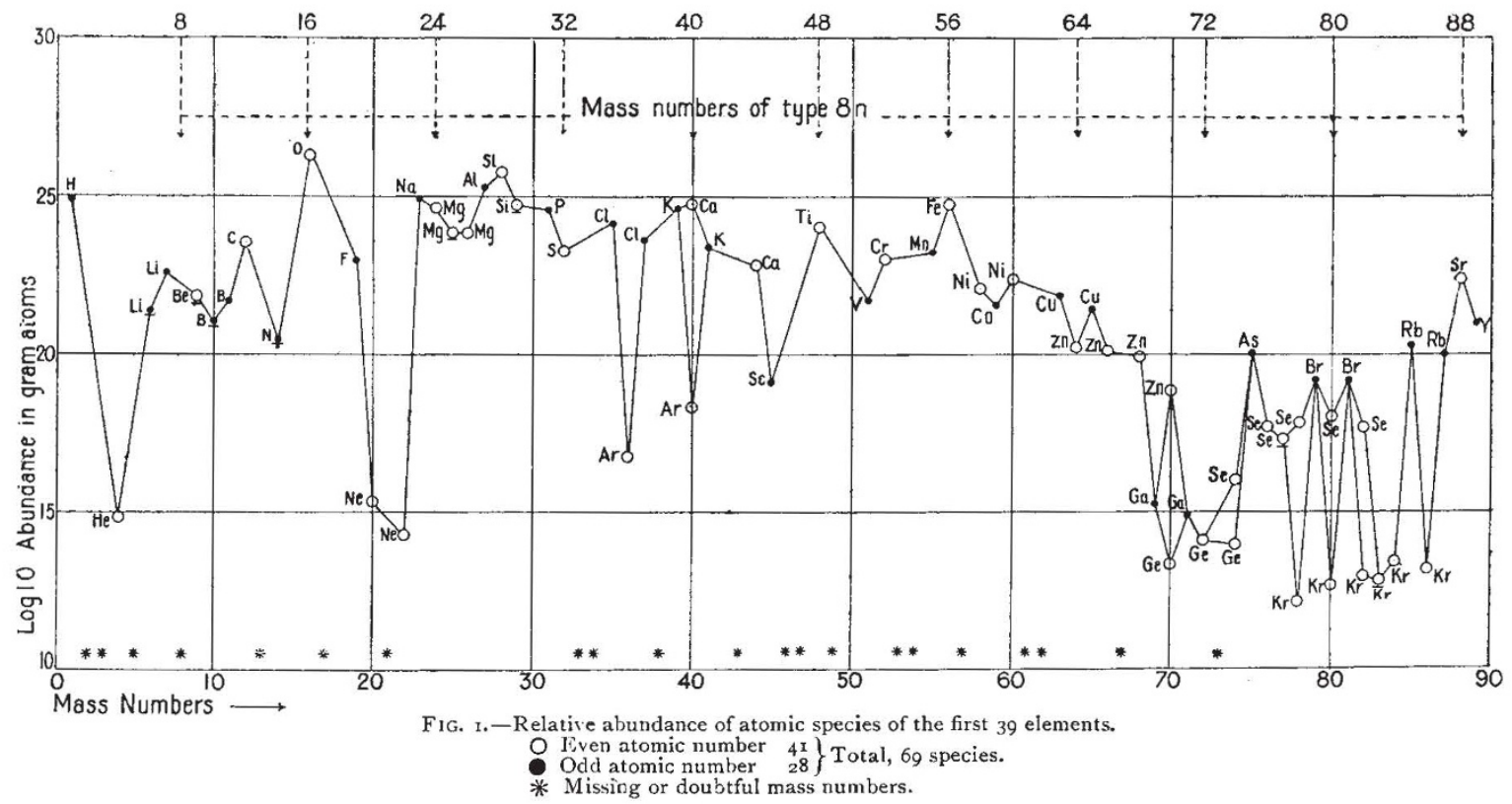

and an atmosphere of mass $5.29 \times 10^{21} \mathrm{gm}$. of ordinary air. That the unknown interior of the earth has the same chemical composition as the deeper parts of its outer crust is, of course, flagrantly improbable, but to leave it out of the calculation altogether might give the hydrosphere and atmosphere undue prominence. The average chemical composition of the igneous rocks is calculated in gram-atoms from the percentage composition given in the admirable report on the subject by Clarke and Washington (No. 462 Geophysical Laboratory, Washington; May I922). Ramsay's and Claude's figures are taken for the atmosphere. In the case of a complex element, the proportion of its various isotopes, when not otherwise ascertainable, is estimated from the intensity of their lines on its mass-spectrum. -This rough method is sufficient for the diagram, for which no great accuracy is claimed. Only the roughest estimates are available for the percentages of the rarer elements in the igneous rocks.

The number of gram-atoms used is clearly a measure of the total number of atoms; we have only to multiply by Avogadro's number 6.06 $\times 10^{23}$ to obtain the latter. Thus in the case of oxygen there are on the earth we out clearly. The appearance of more uniform distribution among the odd atomic numbers than among the even ones is probably largely fictitious, and due to the method of calculating the abundance of the inert gases. Attention may be directed to the scarcity of those types which contain an odd number of electrons in the nucleus. These only number 7 out of a total of 69 , and 4 of these, including all those of even atomic number, occur below atomic number 8 .

The curve was originally drawn in the hope that it might afford some evidence as to the relative stability of nuclei during the evolution of the atoms. In this respect its irregularity is rather disappointing, but consideration of it raises many points of interest. The one with which this article is particularly concerned is perhaps the most obvious of all ; that is, the extreme contrast between the range of abundance exhibited among the different isotopes of one element and that shown among the elements themselves; e.g. there are only about three $\mathrm{Cl}^{35}$ atoms to one $\mathrm{Cl}^{37}$ and about two $\mathrm{Ga}^{69}$ atoms to one $\mathrm{Ga}^{71}$, yet there are a thousand million times more atoms of chlorine than of gallium. The methods of mass-ray analysis are not yet particu- 
larly suitable for detecting atoms present in small quantities among their isotopes, so that a reasonable figure, neglecting exceptionally favourable cases, for the range of abundance between isotopes is $\mathrm{ro}^{2}$. That between elements, even on this table, rises to ${ }^{10}{ }^{14}$, and if the heavier atoms were included, would be vastly greater.

It is curious to reflect how very few would be the number of types of atom known to us by physical methods of mass determination had no chemical methods of separation and concentration been available. The problem is to assign a reason for this gigantic difference of range. If the limitations of the method of detection are the only factors, then we must conclude that the number of atomic species so far discovered is only a minute fraction of those actually existing. This conclusion is interesting in itself, and has some show of probability in the case of elements of even atomic number which show great differences in isotopic complexity, but it does not seem admissible in the case of the others. Twenty-five elements of odd atomic number have been analysed so far; in ten cases two, and in no case more than two, isotopes have been detected. That this can be ascribed simply to the limit of delicacy of the method of detection seems so exceedingly improbable that it appears safer to adopt the view that the number of existing atomic species and their relative abundance shown in this diagram, though of course incomplete, are not on the whole very far wrong.

If this is so, and there are many other pieces of evidence in its support, then there appear only two possible ways of explaining the difference of range under discussion; either our sample of matter is entirely unrepresentative or the similarity between isotopic atoms must be even deeper than has hitherto been supposed. The first alternative would require that natural chemical separation and concentration had taken place to an enormous extent before the earth, or that part of it we are considering, was formed. The relative abundance of the elements in meteorites, which is not very different from that in terrestrial matter, is all against such an idea. The other and more probable alternative is one of fundamental importance and interest. The close abundance-relation between the members of groups of isotopes is most striking, and particularly is it significant in the pairs of odd atomic number, to which may be added those of antimony and silver, not on this diagram. It cannot be due to the mere identity of net nuclear charge, but must be connected in some other way with the structure of the nucleus and its stability in evolution.

It has been suggested that all atoms of the same element may in general contain an "inner nucleus" in common, and that the stability of the inner nucleus will determine the abundance of the element. Further, that this inner part being formed, outer parts may be added to the nucleus in different ways giving rise to isotopes without altering the stability to a large degree. Experimental evidence in support of this idea is already available. The mass relation between the isotopes of tin is apparently integral to the highest accuracy. The same is true of the isotopes of xenon. But the masses of the principal isotopes of tin are not integrally related to the masses of those of xenon, those of tin being the lighter by a quantity which, under the particular conditions of comparison, cannot possibly be ascribed to error of measurement. This is exactly the state of affairs to be expected if the inner nucleus common to the isotopes of tin is lighter than the inner nucleus common to those of xenon. Much more accurate mass determinations will be required to substantiate this theory, which is admittedly speculative, but it seems to supply the only feasible explanation of the facts.

\section{CAPT. T. H. TIZARD, F.R.S.}

CAPT. THOMAS HENRY TIZARD, formerly Assistant Hydrographer of the Navy, died on February $I_{7}$ in his eighty-fifth year. He was the senior surviving officer of the old navigating branch, and came from an old seafaring family. Born at Weymouth on March I 3 , I839, son of Mr. Joseph Tizard, his grandfather commanded an armed merchant vessel at the battle of Copenhagen. Educated at Royal Hospital School, Greenwich, he joined the Navy as master's assistant just seventy years ago, and served in H.M.S. Dragon with the Baltic Fleet during the Russian war of $1854-$ 1856 , being present at the attack on Fort Gustasvard and also at the bombardment of Sveaborg. After the Russian war, Tizard was appointed to H.M.S. Indus on the West Indian station, bearing the flag of Rear-Admiral Sir Houston Stewart, his former captain in the Dragon. Promoted to second master in February I 860 , he returned to England shortly afterwards. Following the inclination of a mathematical and scientific turn of mind, the surveying service had attractions for him, and he was appointed to H.M. surveying vessel Rifleman on the China station. He served in that ship for seven years, during which time

\section{t u a r y.}

he laid the foundation of his subsequent reputation as an accomplished surveyor. The Rifleman was largely engaged on the survey of the reefs and shoals abounding in the South China Sea between Singapore and Manilla, and for some three years Tizard had command of the schooner Saracen, acting as tender to the Rifleman. He was promoted to the rank of master in June 1864 , and returned home three years later suffering severely from dysentery.

In I868-7x Tizard was serving as navigating lieutenant of H.M. surveying vessel Newport, commanded by Capt (later Sir George) Nares on the Mediterranean station, and in September-October I868 directed the laying of a submarine cable between Malta and Alexandria. The Newport was present at the official opening of the Suez Canal in $\mathbf{1} 869$, leading the long procession of ships. During the next three years Tizard was engaged in carrying out a much-needed survey of the Gulf of Suez for the benefit of the vast volume of shipping about to use the new canal route through the Red Sea, a larger vessel, the Shearwater, replacing the Newport. Whilst serving in the Shearwater Tizard conferred a great boon on his brother surveyors by bringing out a "Table of Chords," thereby saving a vast amount of time and arithmetical labour

$$
\text { NO. } 2837 \text {, VOL. I I } 3]
$$

